\title{
Continuing the success of Journal of Endocrinology and Journal of Molecular Endocrinology
}

\section{S Andrikopoulos' ${ }^{1}$, C Farquharson ${ }^{2}$ and M Haluzik $^{3}$}

1Department of Medicine, University of Melbourne, Parkville, Victoria, Australia 2University of Edinburgh-Roslin Institute, Edinburgh, UK

3Diabetes Centre, Institute for Clinical and Experimental Medicine and Institute of Medical Biochemistry and Laboratory Diagnostics, First Faculty of Medicine, Charles University in Prague, Prague, Czech Republic

Correspondence should be addressed to S Andrikopoulos: sof@unimelb.edu.au

\section{Message from the outgoing Co-Editor-in-Chief}

I cannot believe how quickly time has passed, as it has been over 4 years since I took over the Editor-in-Chief role of Journal of Endocrinology and Journal of Molecular Endocrinology (JOE and JME) from Adrian Clark. At that time, the editorial boards had just merged and the senior editorial team was getting settled into handling manuscripts for two journals.

So what have we achieved over the past 4 years or so? We have implemented a Co-Editor-in-Chief structure, with Prof. Colin Farquharson and I sharing the load of triaging and assigning every manuscript that is submitted to JOE and JME. I am pleased to state that the senior editorial team has been extremely hard working and supportive of both Colin and I, ensuring timely and balanced decision making for each manuscript which is being reviewed. This is reflected in the time taken from submission to first decision being 15 days for JOE and 18 days for JME. In addition, the 2018 author survey showed $65 \%$ of respondents rated their experience with JOE and JME as better, or much better, compared with other journals. Finally, the impact factors of both JOE and JME remain very strong at 4.381 and 3.744 respectively, reflecting the excellent scientific content of our journals. These data are satisfying and reflect the enormous input and efforts of both the senior editorial group and the team at Bioscientifica.

We continue to grow the international reputation of the journals and this is highlighted by increased submissions from Asia, Europe, North America and Australia/New Zealand. Furthermore, the senior editorial board reflects this distribution, with representation from China, Singapore, the USA, Australia and New Zealand in addition to the UK and Europe. We continue to put

(C) 2020 Society for Endocrinology Published by Bioscientifica Ltd. Printed in Great Britain much effort into ensuring that the profiles of JOE and JME are prominent, by engaging with other societies, as well as being present at and supporting international scientific meetings. Naturally, in the age of social media the publishing team has established profiles for the journals on Facebook and Twitter, and I encourage you all to use these platforms to engage with the content of the journals.

Publishing continues to be a competitive space with more and more journals being created, competing both for manuscripts and for reviewer time. Despite this, I am pleased to say that we have maintained our high standards and continue to receive and publish excellent research. I am confident that this will ensure the reputations of JOE and JME are maintained and secure their long-term relevance in the field.

I have thoroughly enjoyed my time with the journals, progressing up the ranks from reviewer to editor, senior editor to deputy Editor-in-Chief, to finally being entrusted with the top job. I have particularly enjoyed working closely with Colin as Co-Editors-in-Chief, with the senior editorial team and with Alison Pope at Bioscientifica. Despite some personal and professional challenges, the support and help I received from all these people has allowed me to devote $110 \%$ to my role. I am sad to say goodbye. However, I am extremely happy that Prof. Martin Haluzik from the Czech Republic has agreed to replace me. Martin is an outstanding clinician researcher and his experience and knowledge will be most valuable to the journals. I wish both Colin and Martin all the best as they continue to drive both JOE and JME to higher heights.

Sof Andrikopoulos 


\section{Message from the incoming and current Co-Editors-in-Chief}

Due to the ever increasing submissions to JOE and JME, it was decided that from January 2018 the journals would have two Editors-in-Chief, and it has been my privilege [Colin Farquharson] to serve alongside Sof Andrikopoulos in this role. Prior to 2018, Sof had expertly guided both journals and overseen increases in manuscript submissions worldwide, which resulted in both journals increasing their impact factor in 2018: JOE re-established itself in the top quartile of the Endocrinology \& Metabolism category, with JME maintaining its place. Sof has left both journals in an excellent position for them to move forward with optimism, and we both thank him greatly for his dedication, innovation and hard work in helping make both journals what they are today. From January 2020, Martin Haluzik will replace Sof as Co-Editor-inChief and he will handle all submissions within the field of Diabetes, Metabolism and Obesity. We are indebted to Barbara Clark, our Deputy Editor who, among other roles will continue to have oversight of our review portfolio which makes up a significant percentage of our published material, thereby contributing to the continued success of both journals.

We are acutely aware that authors within our field have an ever-increasing choice of online journals in which to submit their research manuscripts. However, we believe that the international reputation for quality and scientific rigour of our journals, together with continued hard work from the editorial team and our Bioscientifica publishing colleagues, will help us in our aim to maintain both journals as the preferred choice of authors for their valued manuscripts. In return, we offer them a rapid decision from submission to first response. We also strive to give a fair review, and to provide authors with constructive and informative feedback in order to improve their manuscripts. We continue to demand no submission fees, no page charges and no charges for online-only colour figures from our authors. Furthermore, colour print production is discounted for European Society of Endocrinology and Endocrine
Society of Australia members, and is free for Society for Endocrinology members.

We continue to explore novel ways to encourage research submissions from the global research community. Working closely with our Associate Editors situated in all corners of the globe, we aspire to increase the geographical coverage of our submissions, reflecting the developing spread of endocrine excellence. In particular, we welcome and encourage submissions from our colleagues in Africa, the Middle East and Australasia, whilst striving to maintain our submission rates from elsewhere including Asia which remains the region with the highest number of submissions.

For several years the journals have supported and sponsored endocrine-based meetings and workshops throughout the world, and we reward authors publishing in both journals with prizes at our annual Society for Endocrinology meetings. We also continue with our special anniversary issues, which celebrate the major achievements and milestones in endocrinology: in 2020 JME will publish a number of reviews to celebrate 90 Years of Progesterone. This issue will be guest edited by Profs Simak Ali and Bert O'Malley.

So we look forward, with optimism, to producing two high-quality journals for the Society for Endocrinology, which capture the most exciting and novel breakthroughs in endocrine basic and translational science. Whilst we continue to encourage publications in all traditional and developing fields of endocrine enquiry, in the next few years we will have a particular focus on cardiovascular, renal and neurometabolism submissions for JOE, and omics, hormone-dependent cancers and nuclear receptors for JME. In addition to the traditional focus on experimental research, we encourage submissions from translational research areas, including studies in humans that specifically address the pathophysiological mechanisms of endocrine and metabolic diseases.

The journals have now served the endocrine community for 80 years and we look forward with enthusiasm to continuing this mission during our joint stewardship.

Colin Farquharson and Martin Haluzik

Received in final form 30 October 2019

Accepted 30 October 2019

(c) 2020 Society for Endocrinology Published by Bioscientifica Ltd. Printed in Great Britain

https://joe.bioscientifica.com https://doi.org/10.1530/JOE-19-0504 